\title{
Mortars based in different binders with incorporation of phase-change materials: Physical and mechanical properties
}

\author{
Sandra Cunha ${ }^{\mathrm{a} *}$, José Aguiar ${ }^{\mathrm{a}}$, Victor Ferreira ${ }^{\mathrm{b}}$ and António Tadeu ${ }^{\mathrm{c}}$ \\ ${ }^{a}$ Department of Civil Engineering, University of Minho, Guimarães, Portugal; \\ ${ }^{b}$ Department of Civil Engineering, University of Aveiro, Aveiro, Portugal; ${ }^{c}$ Department of Civil \\ Engineering, University of Coimbra, Coimbra, Portugal
}

(Received 6 May 2014; accepted 8 January 2015)

\begin{abstract}
In a society with a high growth rate and increased standards of comfort arises the need to minimise the currently high-energy consumption by taking advantage of renewable energy sources. The mortars with incorporation of phase-change materials (PCM) have the ability to regulate the temperature inside buildings, contributing to the thermal comfort and reduction in the use of heating and cooling equipment, using only the energy supplied by the sun. However, the incorporation of phase-change materials in mortars modifies its characteristics. The main purpose of this study was the production and characterisation in the fresh and hardened state of mortars with incorporation of different contents of PCM in mortars based in different binders. The binders studied were aerial lime, hydraulic lime, gypsum and cement. For each type of binder, different mortars were developed with different content of PCM. The proportion of PCM studied was $0,20,40$ and $60 \%$ of the mass of the sand. It was possible to observe that the incorporation of PCM in mortars caused differences in properties such as workability, microstructure, compressive strength, flexural strength and adhesion.
\end{abstract}

Keywords: phase-change materials (PCM); mortars; physical and mechanical properties

\section{Introduction}

Currently, there is a huge concern about the high-energy consumption, verified in the residential sector associated with heating and cooling needs of buildings. Thus, it becomes imperative to implement constructive solutions that increase energy efficiency in buildings.

The incorporation of phase-change materials (PCM) in mortars for the interior appears as a possible solution in an attempt to solve, or at least minimise, the massive energetic consumption related with buildings. The use of this material allows the regulation of frequency of temperatures' fluctuations, keeping them closer to the desired temperature range for a longer period, using only solar energy as a resource or at least reducing the need to use heating and cooling equipment.

The study of mortars with incorporation of PCM has been a target of study and interest for the scientific community. However, the development and comparison of mortars with incorporation of PCM based in different binders is one of the main knowledge gaps.

*Corresponding author. Email: sandracunha86@gmail.com 
Some studies have been published incorporating PCM in construction products. PCM can be used in solutions for walls, floors and ceilings. There are several authors who had investigated constructive solutions with incorporation of PCM for application on floors. These solutions are varied, such as electric heating under floor systems incorporating polyethylene plates impregnated with PCM, incorporation of PCM in concrete slab and the application of two types of PCM with different transition temperatures (Entrop, Brouwers, \& Reinders, 2011; Jin \& Zhang, 2011; Lin et al., 2005; Sharma, Tyagi, Chen, \& Buddhi, 2009).

The application of PCM in walls is the preferential solution for exploring the potential of these materials. The incorporation of PCM in gypsum plasterboard has been the subject of several studies performed, due to its low cost and various possibilities of application (Athienitis, Liu, Hawes, Banu, \& Feldman, 1997; Darkwa, O’Callaghan, \& Tetlow, 2006; Schossig, Henning, Gschwander, \& Haussmann, 2005; Shilei, Neng, \& Guohui, 2006). Darkwa et al. (2006) investigated the behaviour of two solutions with incorporation of PCM in gypsum plasterboard. In one side, the plasterboard used had $12 \mathrm{~mm}$ of thickness, all impregnated with PCM in order to compare with another situation in which they applied single plasterboards with $10 \mathrm{~mm}$ of thickness, covered by PCM laminate with $2 \mathrm{~mm}$. The amount of PCM incorporated in both cases was the same. The results showed that the use of PCM laminate is more efficient since it contributed to an increase in the minimum temperature. However, other solutions had also been developed like alveolar PVC panels with PCM macroencapsulated, blocks and bricks (Ahmad, Bontemps, Sallée, \& Quenard, 2006; Cabeza, Castell, Barreneche, Gracia, \& Fernández, 2011). Cabeza et al. (2011) constructed and monitored the behaviour of concrete test cells, with and without addition of 5\% of PCM microcapsules. The incorporation of PCM was made in the concrete used on the roof and south and west walls. During the summer and without ventilation, a decrease in maximum temperature and a time lag of about $2 \mathrm{~h}$ were recorded.

The research of potential applications of PCM in mortars has been focused mainly in cement and gypsum compositions (Bentz \& Turpin, 2007; Lucas, Ferreira, \& Aguiar, 2013). The incorporation of PCM in mortars based on aerial lime has already being developed by this research group (Cunha, Aguiar, Ferreira, \& Tadeu, 2013; Cunha, Aguiar, Kheradmend, Bragança, \& Ferreira, 2013; Cunha, Alves, Aguiar, \& Ferreira, 2012).

The thermal behaviour is extremely important; however, the evaluation of the mechanical behaviour is essential for the proper functioning of the mortars. This is a premise for its application and dissemination in the construction industry. The development and comparison of mortars with incorporation of PCM based on aerial lime, hydraulic lime, gypsum and cement was one of the main gaps of knowledge. Thus, the main objective of this work was the development and the physical and mechanical characterisation of mortars with incorporation of PCM based in different binders. Twenty-seven mortars based on different binders and including different contents of PCM were developed. Their physical and mechanical properties were evaluated, such as workability, density, microstructure, water absorption by capillarity, water absorption by immersion, compressive strength, flexural strength and adhesion.

\section{Phase-change materials}

PCM possess the capability to alter its own state as function of the environmental temperature (Zhang, Zhou, Lin, Zhang, \& Di, 2007). In other words, when the 
surrounding environmental temperature of PCM increases until the materials fusion point, it suffers a change from a solid state to a liquid state, absorbing and storing the heat energy from the environment. On the other hand, when the temperature decreases until the PCM solidification point, the material alters from the liquid state to solid state, releasing the previously stored energy to the environment. This application could be made in coating mortars of buildings, with advantage in the passive regulation of internal temperature with increase in thermal inertia (Zalba, Marín, Cabeza, \& Mehling, 2003).

The PCM must be encapsulated, for its correct use; otherwise, during the liquid phase, there is a possibility that it moves from the original area of application. There are two main forms of encapsulation, macroencapsulation and microencapsulation. The macroencapsulation is based in the introduction of PCM into tubes, panels or other large containers. It is usually done in containers with more than $1 \mathrm{~cm}$ in diameter and presents a better compatibility with the material, improving the handling in construction (Cabeza et al., 2011). The microencapsulation of PCM consists on covering the material particles, with a material, usually a polymer, commonly known capsule, with dimensions between 1 and $60 \mu \mathrm{m}$. The polymer used could be polymethylmethacrylate, polyuria or polyurethane and should respond at some demands of operation, as high heat transfer. The microcapsules can be spherical or asymmetric and with variable shape. The advantage of this encapsulation process is the improvement of heat transfer, through its large surface area (Cabeza et al., 2011; Tyagi, Kaushik, Tyagi, \& Akiyama, 2011).

In 1983, emerged the first classification of substances used for thermal storage. These are classified as organic, inorganic and eutectic mixtures. Organic materials can be non-paraffinic or paraffinic. Usually, they have congruent phase changes without degradation. The inorganic materials are classified as hydrated salts and metals. The eutectic mixtures result from the combination of two or more compounds of organic and/or inorganic nature. By this way, it is possible to correspond to the need of more suitable transition temperatures for the demands (Cabeza et al., 2011; Sharma et al., 2009).

Sustainable development is closely connected to three dimensions: economic, social and environmental. It is important to have a balance and harmony between them. The creation of a strong connection between the construction industry and the pillars of sustainable development is particularly important and early started to merit the attention of stakeholders in the construction sector. The incorporation of PCM microcapsules in mortars brings social, economic and environmental benefits, demonstrating a significant contribution to a construction with a higher value of sustainability. The social benefits derive from the thermal comfort increase inside buildings, given that nowadays this is an important requirement and frequently demanded by buyers and potential sellers as an important decision parameter. The increase in thermal comfort is achieved by the thermal capacity of the PCM, allowing store and release of energy, keeping the interior temperature sensibly constant, or at least with less variation. The environmental aspect concerns the fossil fuels depletion, given that this technology aims at maintaining constant temperatures inside the building, consequently leading to a decrease in air conditioning equipment usage. The economic benefit is related to the technology adequacy and implementation costs. These should be supported and easily amortised by the user. It may also be noted that the economic benefits of reduced energy consumption and lag times for lower demand are evident and can be achieved with the use of PCM. 


\section{Materials, compositions, fabrication and methodology}

\subsection{Materials}

The selection of the materials took in account previous works (Cunha, Aguiar, Ferreira, et al., 2013; Cunha, Aguiar, Kheradmand, et al., 2013; Cunha et al., 2012). In order to understand the influence of adding PCM in mortars, mortars for interior coating were developed based on the following binders: aerial lime, hydraulic lime, gypsum and cement. The aerial lime used has a purity of $90 \%$ and density of $2450 \mathrm{~kg} / \mathrm{m}^{3}$. The gypsum used is a traditional one, with high fineness and density of $2740 \mathrm{~kg} / \mathrm{m}^{3}$. The hydraulic lime was a natural lime (NHL5) with density of $2550 \mathrm{~kg} / \mathrm{m}^{3}$. Two types of cement were also used: CEM II B-L $32.5 \mathrm{~N}$ and CEM I 42.5R with density of $3030 \mathrm{~kg} / \mathrm{m}^{3}$.

The PCM used is composed of a wall in melamine-formaldehyde and a core in paraffin (Figure 1), with temperature transition of about $22.5^{\circ} \mathrm{C}$ and enthalpy of $147.9 \mathrm{~kJ} / \mathrm{kg}$. These exhibit a transition temperature of $24^{\circ} \mathrm{C}$ in the heating cycle and $21{ }^{\circ} \mathrm{C}$ in the cooling cycle. The process of fabrication is polycondensation by addition and the material is commercialised by the Devan Chemicals, with the commercial name of Mikathermic D24. The dimensions of PCM microcapsules were evaluated by granulometry tests, using a laser particle size analyser. It was possible to observe a particle size distribution between 5.8 and $339 \mu \mathrm{m}$, with $80 \%$ of particle size between 10.4 and $55.2 \mu \mathrm{m}$ (Figure 2). The average particle size is $43.91 \mu \mathrm{m}$.

The superplasticiser used was a polyacrylate, with a density of $1050 \mathrm{~kg} / \mathrm{m}^{3}$. The sand used has an average particle size of $439.9 \mu \mathrm{m}$ and a density of $2600 \mathrm{~kg} / \mathrm{m}^{3}$. Based on granulometric distribution, the parameters D50, D10 and D90 were obtained. The D10 correspond to $150 \mu \mathrm{m}, \mathrm{D} 50$ correspond to $310 \mu \mathrm{m}$ and the D90 correspond to $480 \mu \mathrm{m}$. Finally, the fibres used are synthetic fibres of polyamide, with a length of $6 \mathrm{~mm}$, a $22.3 \mu \mathrm{m}$ of thickness and a density of $1380 \mathrm{~kg} / \mathrm{m}^{3}$.

\subsection{Compositions, fabrication and methodology}

In order to develop this study, an experimental campaign was considered, with the main goal of characterising the produced compositions. Twenty-seven compositions were

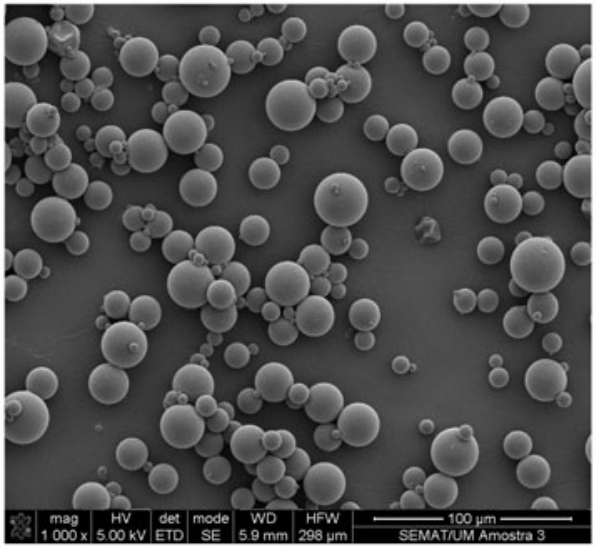

(a)

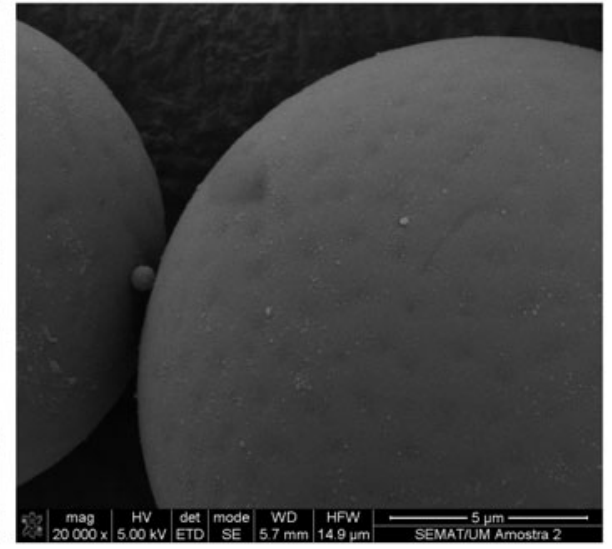

(b)

Figure 1. Microscope observation of polymer surface of the microcapsules: (a) Enlargement of $1000 \times$ (b) Enlargement of $20000 \times$. 


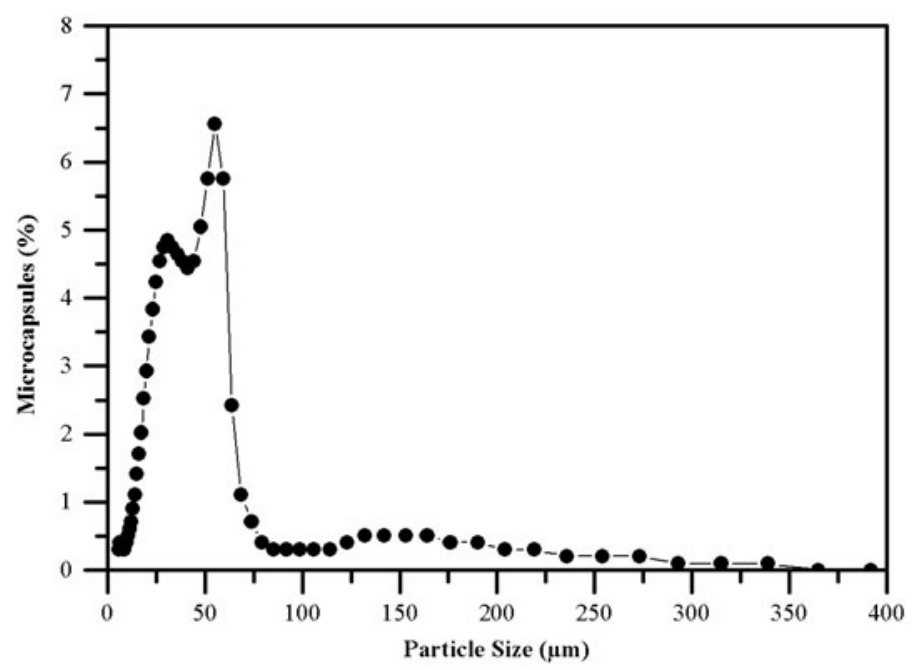

Figure 2. Particle size distribution of PCM microcapsules.

developed taking account the future application of the mortar for interior coating. These compositions were evaluated from the fresh state up to 28 days.

The PCM content was fixed in $0,20,40$ and $60 \%$ of total mass of aggregate. In order to overcome some of the problems related with the mortar shrinkage and consequent cracking, polyamide fibres and superplasticiser were incorporated. The content of PCM, fibres and superplasticiser was based in previous works (Cunha, Aguiar, Ferreira, et al., 2013; Cunha, Aguiar, Kheradmand, et al., 2013; Cunha et al., 2012).

The studied compositions are presented in Table 1. The study used compositions with different contents of PCM and different binders.

The mixture procedure and specimens preparation for the compression and flexural tests were performed in accordance with the standard EN 1015-11 (European Committee for Standardization, 1999). For each composition, three prismatic specimens with $40 \times$ $40 \times 160 \mathrm{~mm}^{3}$ were prepared.

Regarding the adhesion tests, the mixture procedure and specimens preparation was performed in accordance to the standard EN 1015-12 (European Committee for Standardization, 2000). For each studied composition, five circular test areas with a diameter of $50 \mathrm{~mm}$ were prepared. After their preparation, all the specimens were stored for 7 days in polyethylene bags, and subsequently placed in the laboratory at regular room temperature (about $22{ }^{\circ} \mathrm{C}$ ) for 21 days.

The observation of the microstructure of developed mortars was performed using a scanning electron microscope. For each composition, two cylindrical specimens with diameter and height of approximately $1 \mathrm{~cm}$ were prepared.

The flexural and compressive behaviour was determined based in the standard EN 1015-11 (European Committee for Standardization, 1999). The flexural tests were performed with load control at a speed of $50 \mathrm{~N} / \mathrm{s}$. Compressive tests were realised through the application of a load on the specimen with resource to a metallic piece, rigid enough to make the vertical load uniform. The specimens used for the test were the half parts resulting from the flexural test. The compressive tests were performed with a load control at a speed of $150 \mathrm{~N} / \mathrm{s}$. 
Table 1. Mortars formulation $\left(\mathrm{kg} / \mathrm{m}^{3}\right)$.

\begin{tabular}{llrrrrrc}
\hline Composition & \multicolumn{1}{c}{ Binder } & & Sand & PCM & SP & Fibres & Water/Binder \\
\hline CA500-0PCM & Aerial lime & 500 & 1447.2 & 0 & 15 & 0 & .45 \\
CA500-20PCM & Aerial lime & 500 & 893.4 & 178.7 & 15 & 0 & .47 \\
CA500-40PCM & Aerial lime & 500 & 597.8 & 239.1 & 15 & 0 & .56 \\
CA500-60PCM & Aerial lime & 500 & 456.3 & 273.8 & 15 & 0 & .59 \\
CA600-40PCM & Aerial lime & 600 & 550.5 & 220.2 & 18 & 0 & .46 \\
CA700-40PCM & Aerial lime & 700 & 485.3 & 194.1 & 21 & 0 & .41 \\
CA800-40PCM & Aerial lime & 800 & 451.2 & 180.5 & 24 & 0 & .34 \\
CA800-40PCM-F & Aerial lime & 800 & 425.2 & 170.1 & 24 & 8 & .36 \\
CH500-0PCM & Hydraulic lime & 500 & 1351.1 & 0 & 15 & 0 & .54 \\
CH500-20PCM & Hydraulic lime & 500 & 841.1 & 168.2 & 15 & 0 & .55 \\
CH500-40PCM & Hydraulic lime & 500 & 571.6 & 228.6 & 15 & 0 & .62 \\
CH500-40PCM-F & Hydraulic lime & 500 & 567.2 & 226.9 & 15 & 5 & .62 \\
CH500-60PCM & Hydraulic lime & 500 & 431.0 & 258.6 & 15 & 0 & .66 \\
C32.5N500-0PCM & CEM II B-L 32.5N & 500 & 1418.8 & 0 & 15 & 0 & .55 \\
C32.5N500-20PCM & CEM II B-L 32.5N & 500 & 924.5 & 184.9 & 15 & 0 & .51 \\
C32.5N500-40PCM & CEM II B-L 32.5N & 500 & 644.3 & 257.7 & 15 & 0 & .56 \\
C32.5N500-40PCM-F & CEM II B-L 32.5N & 500 & 622.2 & 248.8 & 15 & 5 & .59 \\
C32.5N500-60PCM & CEM II B-L 32.5N & 500 & 488.3 & 292.9 & 15 & 0 & .60 \\
C42.5R500-0PCM & CEM I 42.5R & 500 & 1470.8 & 0 & 15 & 0 & .51 \\
C42.5R500-20PCM & CEM I 42.5R & 500 & 924.5 & 184.9 & 15 & 0 & .51 \\
C42.5R500-40PCM & CEM I 42.5R & 500 & 632.4 & 252.9 & 15 & 0 & .58 \\
C42.5R500-60PCM & CEM I 42.5R & 500 & 483.6 & 290.2 & 15 & 0 & .61 \\
G500-0PCM & Gypsum & 500 & 1360.4 & 0 & 15 & 0 & .56 \\
G500-20PCM & Gypsum & 500 & 830.6 & 166.1 & 15 & 0 & .59 \\
G500-40PCM & Gypsum & 500 & 540.1 & 216.0 & 15 & 0 & .70 \\
G500-40PCM-F & Gypsum & 500 & 535.8 & 214.3 & 15 & 5 & .70 \\
G500-60PCM & Gypsum & 500 & 396.9 & 238.1 & 15 & 0 & .76 \\
\hline & & & & & & & \\
\hline
\end{tabular}

The adhesion tests were performed based on the standard EN 1015-12 (European Committee for Standardization, 2000). It was possible to estimate the adhesion of mortar at 28 days, when applied to a ceramic substrate frequently used in the construction industry to perform masonry. The tests were performed only for the reference compositions $(0 \%$ PCM) and those with incorporation of $40 \%$ of PCM and $1 \%$ of polyamide fibres, since the compositions with incorporation of $40 \%$ of PCM and without addition of fibres showed cracks in surface related to shrinkage, making impossible to perform these tests.

The water absorption by capillarity tests was performed based on the European standard EN 1015-18 (European Committee for Standardization, 2002). The samples were obtained by cutting the prismatic specimens with dimensions of $40 \times 40 \times 160 \mathrm{~mm}^{3}$, previously subjected to flexural tests. For each composition, three specimens were prepared, resulting in six samples after flexural tests. The test was performed for each binder, for the reference mortars, mortars with $40 \%$ of PCM, and mortars with $40 \%$ of PCM and fibres. For each specimen, it was decided to put the failure surface resulting from the flexural test in contact with the water. Thus, it was possible to ensure that the porosity present in the surface in contact with the water was close to the real porosity present in the studied mortars. This removes the possibility of analysing one surface with higher content of material of small dimensions, which would affect the results of these tests. The quantification of absorbed water was performed by conducting successive weightings in specimens. These weight measurements were made according to a 
previously established weighting plan, beginning with the first contact of the specimens with water. In order to evaluate the progress of water absorption until the weight stabilisation, periodic measurements were performed during 9 days.

The water absorption by immersion tests were based in the specification LNEC E 394 (National Laboratory of Civil Engineering, 1993). The samples were obtained by cutting the prismatic specimens with dimensions of $40 \times 40 \times 160 \mathrm{~mm}^{3}$, previously subjected to flexural tests. For each composition, three specimens were prepared, resulting in six samples after flexural tests.

Initially, the specimens were dried in oven until the constant mass. Subsequently, they were saturated with resource to a container with water at a temperature of $20 \pm 3{ }^{\circ} \mathrm{C}$. Finally, after saturation it was determined the hydrostatic mass.

\section{Test results and discussion}

\subsection{Workability}

The workability tests were performed with the main goal of verifying the adequacy of application of the developed mortars. The tests were performed based on the flow table method stated by the European standard EN 1015-3 (European Committee for Standardization, 2004). The resulting value within the test was only considered when between 200 and $220 \mathrm{~mm}$.

According to Figure 3, it was possible to identify changes in the amount of water added to the mortars with the incorporation of PCM microcapsules.

It was possible to verify an increase in water/binder ratio with the incorporation of PCM microcapsules. The incorporation of $20 \%$ of PCM microcapsules causes an increase in the amount of water of about $5 \%$. However, the incorporation of higher contents of PCM leads to a greater increase into water requirement. This can be explained by the reduced particle dimension of the used PCM and by the water absorption of the polymeric wall of the microcapsule.

The gypsum-based mortars present higher ratios of water/binder and the aerial limebased mortars exhibit lower contents of water. The lower water/binder ratio present in the aerial lime-based mortars can be explained by the presence of a higher content of superplasticiser.
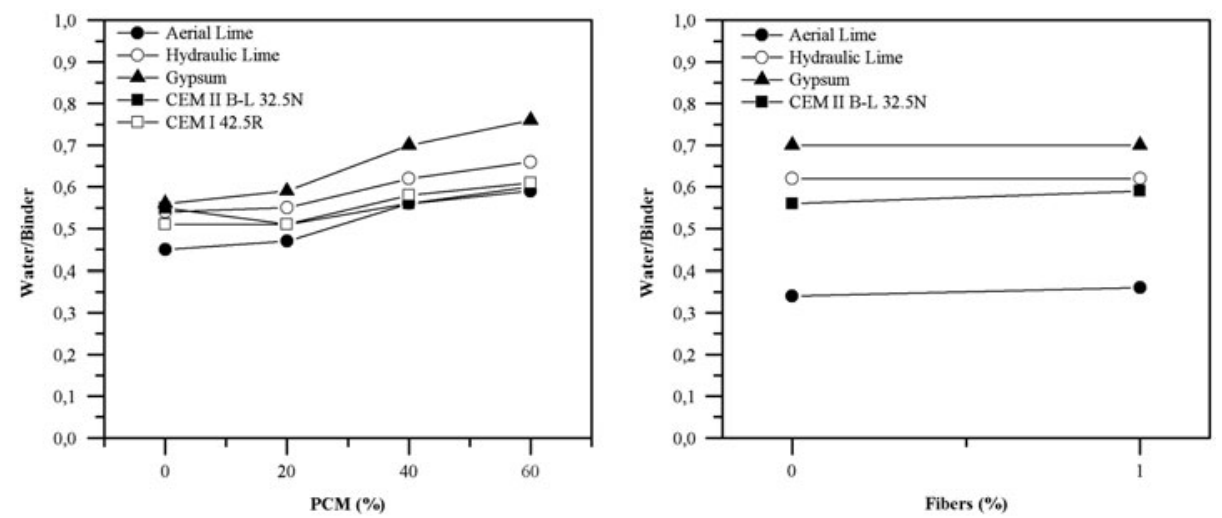

Figure 3. Workability of developed mortars. 
For the used range of fibres fraction, the incorporation of this material in the mortars with PCM did not cause significant changes in the amount of water added to the mortar; however, there was a slight reduction in the flow diameter obtained.

\subsection{Density}

Regarding to the density of the different mortars, it was possible to observe a reduction of its value with the increase in the PCM content (Figure 4). The incorporation of $20 \%$ of PCM causes a decrease in about $16 \%$ in all tested binders. This behaviour can be explained by the low weight of the PCM and the increase in the quantity of water used to produce the mortar. The incorporation of fibres did not cause changes in the density because the content used in each composition is low.

\subsection{Flexural and compressive behaviour}

According to the results (Figure 5), it was possible to observe a decrease in mechanical properties caused by the introduction of PCM microcapsules. This behaviour can be justified by the increase in the water/binder ratio due to the introduction of a higher content of PCM which caused higher porosity in mortars.

Concerning the flexural strength, the incorporation of $20 \%$ of PCM microcapsules resulted in a decrease in flexural superior to $23 \%$, with exception of cement CEM II $32.5 \mathrm{~N}$ B-L-based mortars which decrease only about $3 \%$.

Regarding the compressive strength, all tested binders showed also a significant decrease with the incorporation of PCM. The incorporation of $20 \%$ of PCM microcapsules revealed a decrease in the compressive strength at least $37 \%$ when compared to the reference mortar.

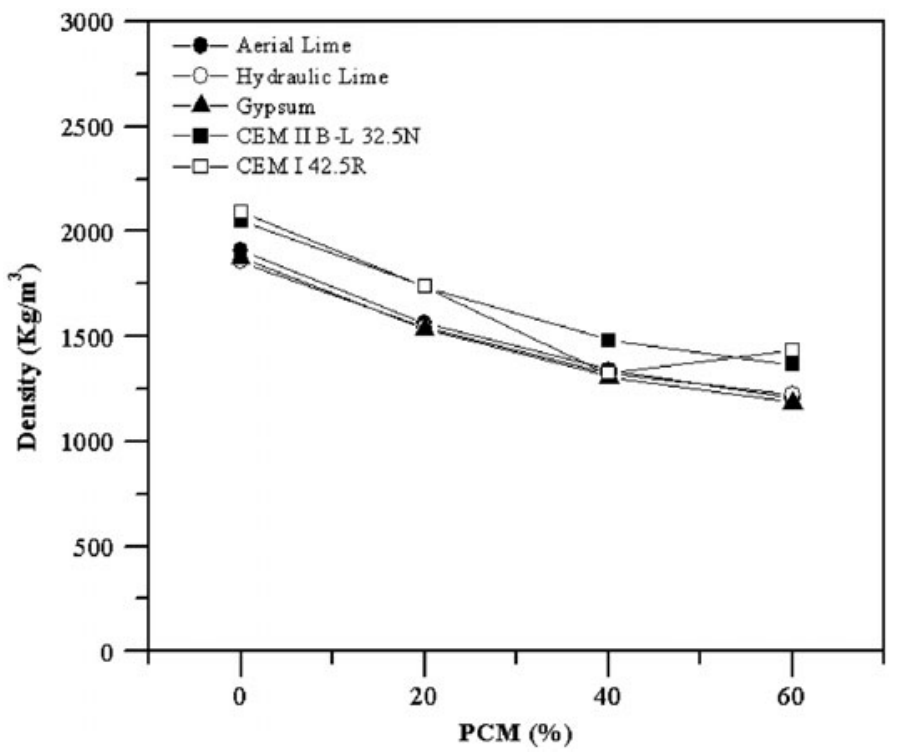

Figure 4. Density of developed mortars. 

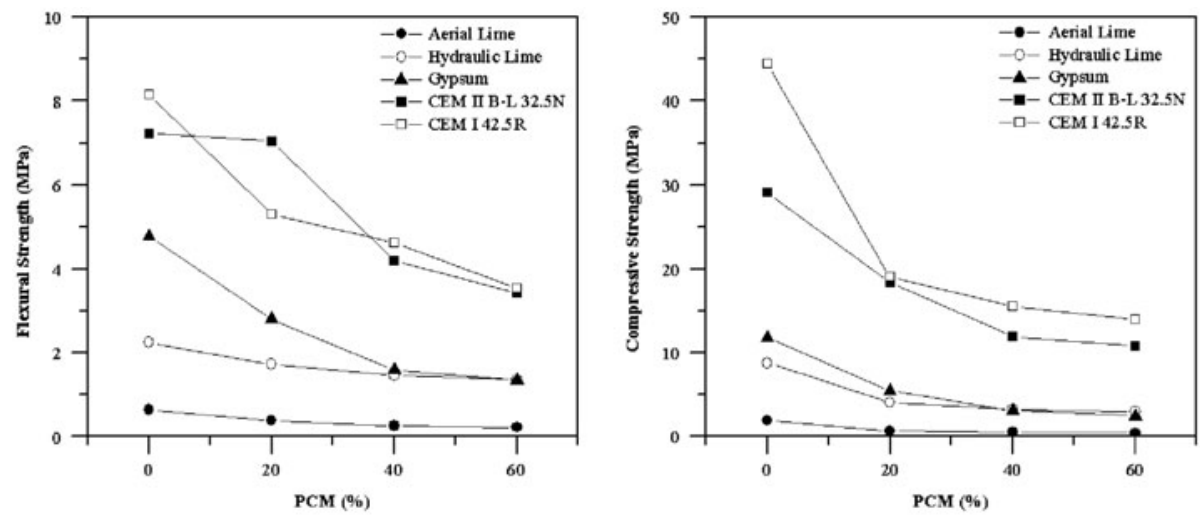

Figure 5. Flexural and compressive behaviour in mortars with incorporation of PCM.

The binder which presented lower losses of flexural and compressive strength was the cement CEM II $32.5 \mathrm{~N}$ B-L.

The incorporation of polyamide fibres in mortars (Figure 6) led to an increase in the flexural strength of about $51 \%$ for aerial lime-based mortars. The mortars based on hydraulic lime, gypsum and cement did not show any influence associated with this addition. The improvement observed essentially for aerial lime-based mortars is related to the capacity of fibres to oppose the formation of cracks. This can be due to high quantity of binders into these mortars. On the other hand, the incorporation of fibres led to an increase in the compressive strength for aerial lime-based mortars. However, this behaviour is related to the presence of higher dosage of binder in the mortar with incorporation of PCM microcapsules, because it was necessary to increase the content of binder to obtain an adequate classification. The remaining binders showed a residual decrease in the compressive strength. In these cases, it was possible consider that the incorporation of polyamide fibres was not beneficial.

In order to evaluate the influence of the presence of PCM in the compression strength classification, the mortars were classified according to standard NP EN 998-1 (Tables 2 and 3) (Portuguese Institute for Quality, 2013). The premise of this work was
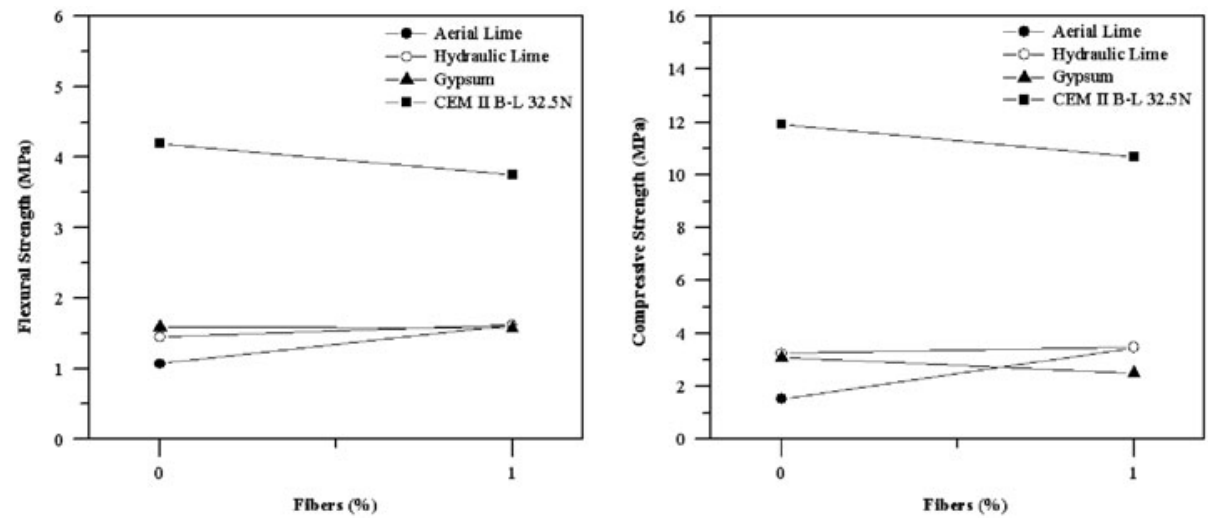

Figure 6. Flexural and compressive behaviour in PCM mortars with incorporation of fibres. 
Table 2. Classification of mortars according to standard NP EN 998-1:2010.

Class of strength

Compression strength $(\mathrm{MPa})$

CSI

CSII

$.4-2.5$

$1.5-5.0$

CSIII

$3.5-7.5$

CSIV

$\geq 6.0$

to obtain mortars with a minimum classification of CSII. It was possible to observe that the incorporation of PCM resulted in a lower classification. For all tested binders, it was possible to observe a classification equal or higher than CSII, with the exception of the aerial lime-based mortars which has a classification of CSI for mortars with PCM with a content of binder lower than $800 \mathrm{~kg} / \mathrm{m}^{3}$.

The incorporation of PCM resulted in a lower classification, with the exception of cement-based mortars which always correspond to the maximum class (CSIV). Nevertheless, this binder still resulted in a decrease in the total compressive strength.

\subsection{Adhesion}

According Figure 7 and Table 4, it was possible to observe a decrease in adhesion with the incorporation of PCM microcapsules. The incorporation of $40 \%$ PCM leads to a

Table 3. Classification of mortars according with the compressive strength (NP EN 998-1:2010).

\begin{tabular}{|c|c|c|c|}
\hline Composition & Binder & $\begin{array}{l}\text { Compression } \\
\text { strength (MPa) }\end{array}$ & $\begin{array}{l}\text { Classification NP } \\
\text { EN 998-1:2010 }\end{array}$ \\
\hline CA500-0PCM & Aerial lime & 1.90 & CS II \\
\hline CA500-20PCM & Aerial lime & .68 & CS I \\
\hline CA500-40PCM & Aerial lime & .51 & CS I \\
\hline CA500-60PCM & Aerial lime & .45 & CS I \\
\hline CA600-40PCM & Aerial lime & 1.09 & CS I \\
\hline CA700-40PCM & Aerial lime & 1.18 & CS I \\
\hline CA800-40PCM & Aerial lime & 1.53 & CS II \\
\hline CA800-40PCM-F & Aerial lime & 3.46 & CS II \\
\hline CH500-0PCM & Hydraulic lime & 8.76 & CS IV \\
\hline CH500-20PCM & Hydraulic lime & 4.04 & CS III \\
\hline CH500-40PCM & Hydraulic lime & 3.24 & CS II \\
\hline CH500-40PCM-F & Hydraulic lime & 3.48 & CS II \\
\hline CH500-60PCM & Hydraulic lime & 2.99 & CS II \\
\hline C32.5N500-0PCM & CEM II B-L $32.5 \mathrm{~N}$ & 29.05 & CS IV \\
\hline C $32.5 \mathrm{~N} 500-20 \mathrm{PCM}$ & CEM II B-L 32.5N & 18.34 & CS IV \\
\hline C $32.5 \mathrm{~N} 500-40 \mathrm{PCM}$ & CEM II B-L 32.5N & 11.91 & CS IV \\
\hline C32.5N500-40PCM-F & CEM II B-L $32.5 \mathrm{~N}$ & 10.69 & CS IV \\
\hline C32.5N500-60PCM & CEM II B-L 32.5N & 10.81 & CS IV \\
\hline C42.5R500-0PCM & CEM I 42.5R & 44.40 & CS IV \\
\hline C42.5R500-20PCM & CEM I 42.5R & 19.01 & CS IV \\
\hline C42.5R500-40PCM & CEM I 42.5R & 15.50 & CS IV \\
\hline C42.5R500-60PCM & CEM I 42.5R & 13.90 & CS IV \\
\hline G500-0PCM & Gypsum & 11.78 & CS IV \\
\hline G500-20PCM & Gypsum & 5.48 & CS III \\
\hline G500-40PCM & Gypsum & 3.10 & CS II \\
\hline G500-40PCM-F & Gypsum & 2.49 & CS II \\
\hline G500-60PCM & Gypsum & 2.42 & CS II \\
\hline
\end{tabular}




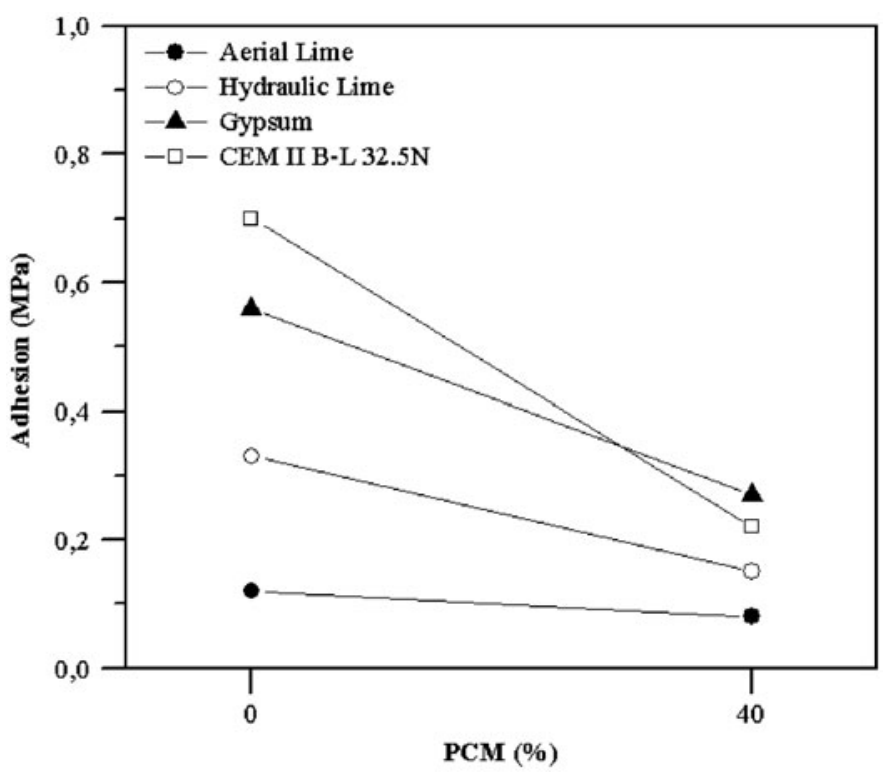

Figure 7. Adhesion of developed mortars.

Table 4. Adhesion strength of mortars.

\begin{tabular}{llc}
\hline Composition & Binder & Adhesion (MPa) \\
\hline CA500-0PCM & Aerial lime & .12 \\
CA800-40PCM-F & Aerial lime & .08 \\
CH500-0PCM & Hydraulic lime & .33 \\
CH500-40PCM-F & Hydraulic lime & .15 \\
C32.5N500-0PCM & CEM II B-L 32.5N & .70 \\
C32.5N500-40PCM-F & CEM II B-L 32.5N & .22 \\
G500-0PCM & Gypsum & .56 \\
G500-40PCM-F & Gypsum & .27 \\
\hline
\end{tabular}

decrease in the value of adhesion of about 33\%. This behaviour can be justified by the increase in the water/binder ratio due to the introduction of a higher content of PCM which caused higher porosity in mortars.

The hydraulic lime-based mortars presented a cohesive failure in the mortar. Contrarily, the aerial lime-based mortars and the gypsum-based mortars showed an adhesive failure in the interface between the mortar and the substrate. Finally, the cement-based mortars presented a cohesive failure in the substrate.

\subsection{Water absorption by capillarity}

According to Table 5 and Figure 8, it was possible to verify that the gypsum-based mortars present the higher coefficient of water absorption by capillarity. Simultaneously, the cement-based mortars show the lower coefficient of water absorption by capillarity compared with the mortars based on the other binders. 
Table 5. Capillary absorption coefficient $\left(\mathrm{kg} /\left(\mathrm{m}^{2} \min ^{0.5}\right)\right.$.

\begin{tabular}{llc}
\hline Composition & Binder & Capillary absorption coefficient $\left[\mathrm{kg} /\left(\mathrm{m}^{2} \mathrm{~min}^{0.5}\right)\right]$ \\
\hline CA500-0PCM & Aerial lime & .22 \\
CA800-40PCM & Aerial lime & .24 \\
CA800-40PCM-F & Aerial lime & .23 \\
CH500-0PCM & Hydraulic lime & .34 \\
CH500-40PCM & Hydraulic lime & .29 \\
CH500-40PCM-F & Hydraulic lime & .28 \\
C32.5N500-0PCM & CEM II B-L 32.5N & .12 \\
C32.5N500-40PCM & CEM II B-L 32.5N & .08 \\
C32.5N500-40PCM-F & CEM II B-L 32.5N & .03 \\
G500-0PCM & Gypsum & .94 \\
G500-40PCM & Gypsum & 1.10 \\
G500-40PCM-F & Gypsum & .96 \\
\hline
\end{tabular}

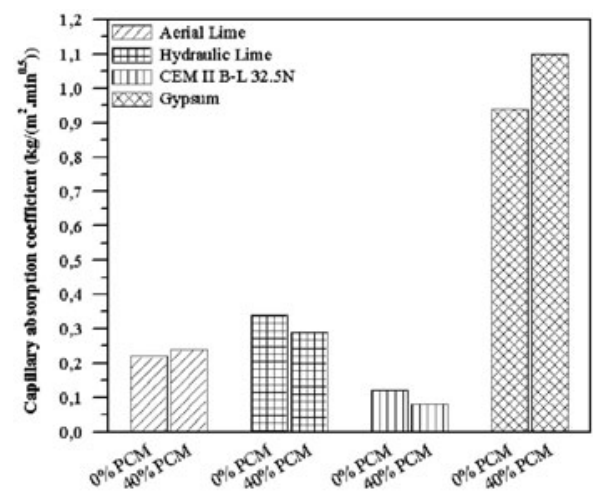

(a)

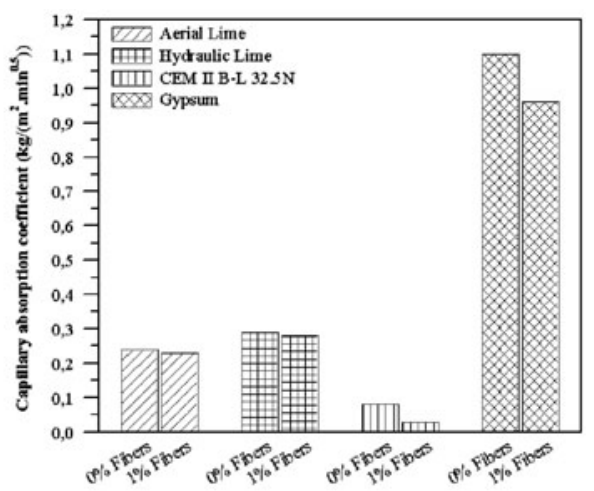

(b)

Figure 8. Capillary absorption coefficient: (a) Variation with PCM content (b) Variation with fibres content.

The incorporation of $40 \%$ of PCM caused a decrease in the capillary absorption coefficient of $15 \%$ in hydraulic lime-based mortars and $33 \%$ in the cement-based mortars. On the other hand, it was also possible to observe an increase in capillary absorption coefficient of $9 \%$ for aerial lime-based mortars and 17\% for gypsum-based mortars.

The incorporation of $1 \%$ of polyamide fibres had the main objective of control the shrinkage in the developed mortars. Their presence in mortars caused a decrease in the capillary absorption coefficient of about $4 \%$ in the aerial lime-based mortars, $13 \%$ in the gypsum-based mortars and $63 \%$ in the cement-based mortars. The hydraulic limebased mortars did not present any change in the capillary absorption coefficient with the incorporation of fibres. This situation can be explained by the ability of fibres to mitigate micro-cracking of the mortars, reducing the effect of the presence of a higher ratio water/binder.

Figure 9 shows the behaviour of the studied mortars during the 9 days of testing. According with the results of the coefficient of water absorption by capillarity, it was possible to observe once again that the gypsum-based mortars have a faster saturation 


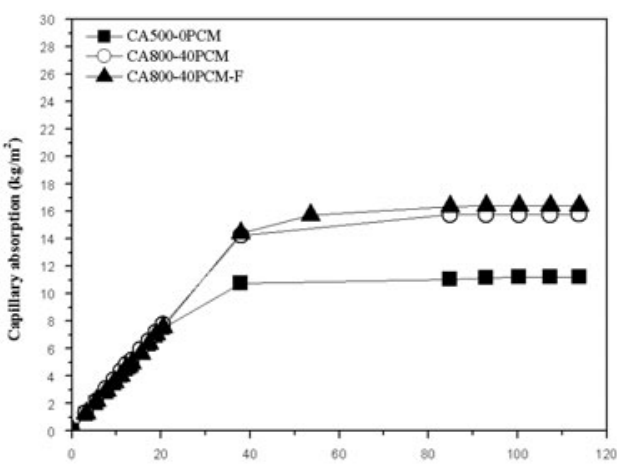

(a)

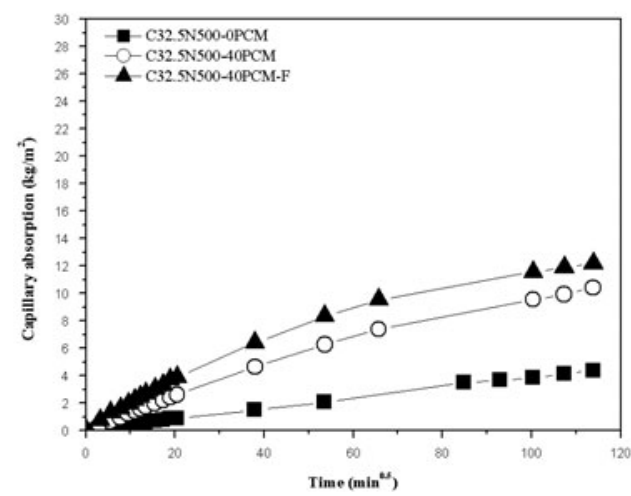

(c)

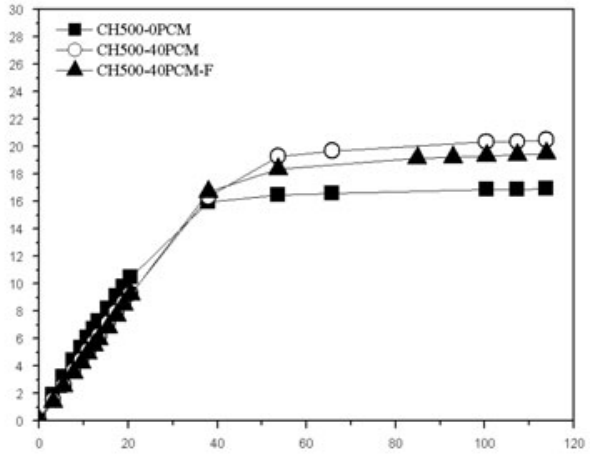

(b)

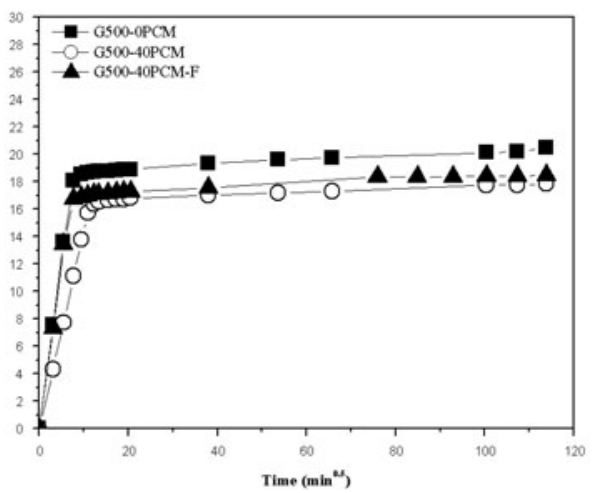

(d)

Figure 9. Water absorption by capillarity: (a) Aerial lime-based mortars (b) Hydraulic lime-based mortars (c) Cement-based mortars (d) Gypsum-based mortars.

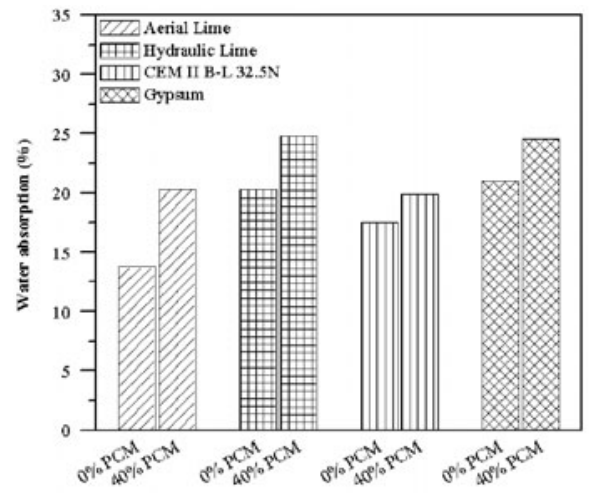

(a)

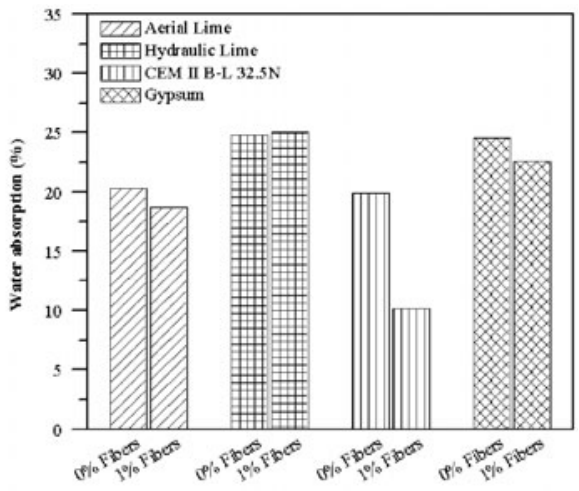

(b)

Figure 10. Water absorption of the mortars: (a) Variation with PCM content (b) Variation with fibres content. 


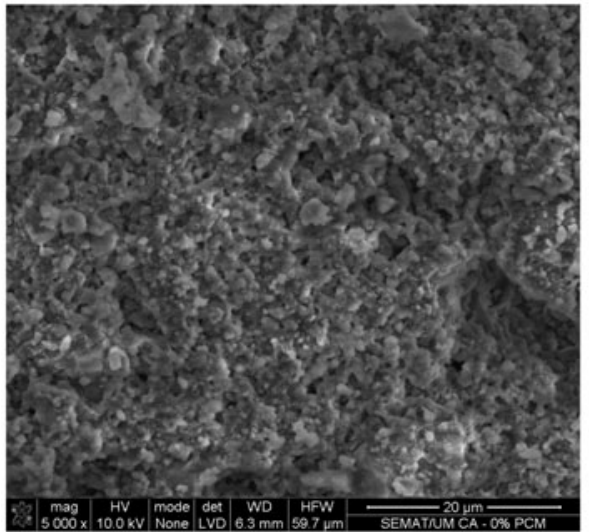

(a)

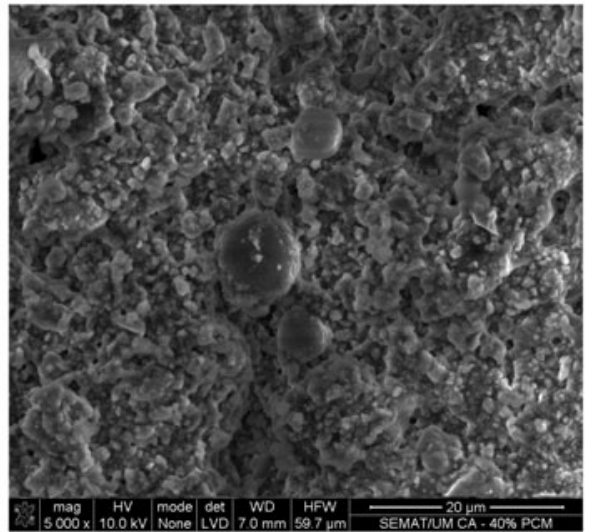

(b)

Figure 11. Microstructure of aerial lime-based mortars: (a) Mortar without incorporation of PCM microcapsules (b) Mortar with incorporation of $40 \%$ of PCM microcapsules.

process, presenting all specimens saturated after $150 \mathrm{~min}$ in contact with water. The cement-based mortars showed a slower velocity of saturation, tending to stabilise after 7 days of testing.

\subsection{Water absorption by immersion}

Regarding Figure 10, it is possible to observe that the incorporation of $40 \%$ of PCM microcapsules in mortars caused an increase in water absorption greater than $14 \%$.

However, the incorporation of $1 \%$ polyamide fibres resulted in a slight decrease in water absorption, with the exception of cement-based mortars, which value decreased $49 \%$. It was also possible to identify that the gypsum-based mortars and hydraulic

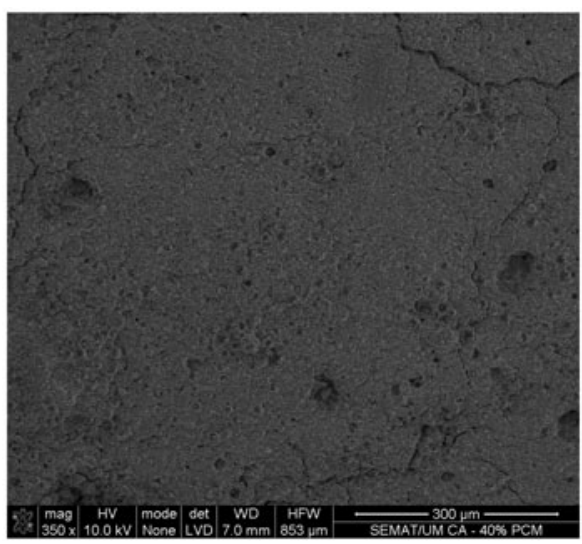

(a)

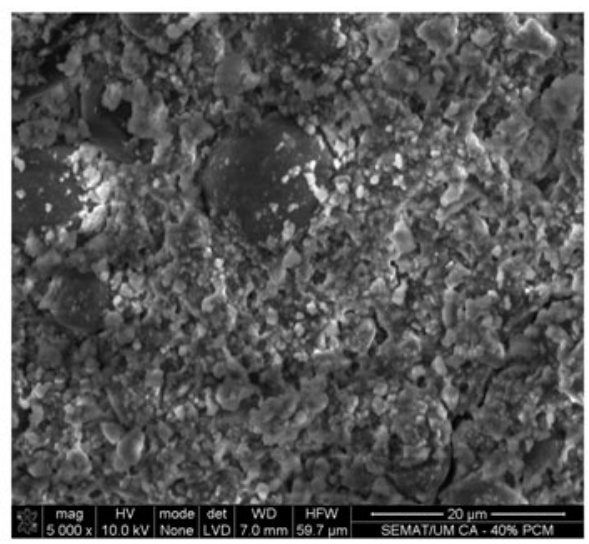

(b)

Figure 12. Cracking caused by shrinkage in the aerial lime-based mortars: (a) Enlargement of $350 \times$ (b) Enlargement of $20000 \times$. 


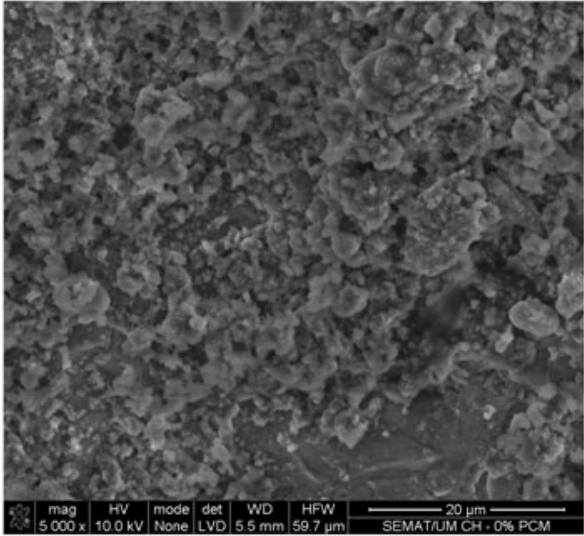

(a)

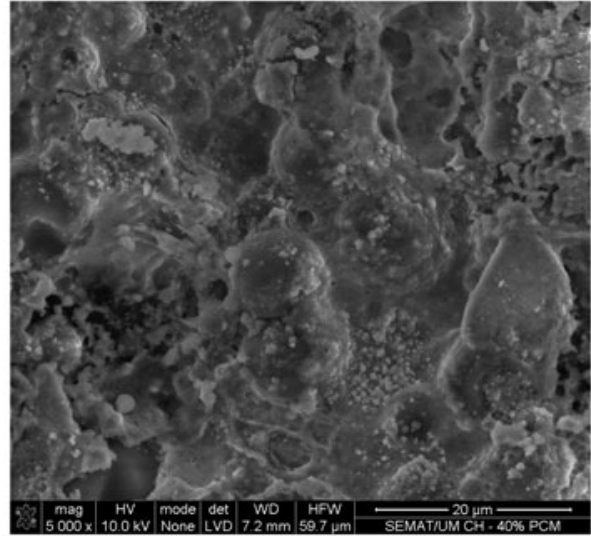

(b)

Figure 13. Microstructure of hydraulic lime-based mortars: (a) Mortar without incorporation of PCM microcapsules, (b) Mortar with incorporation of $40 \%$ of PCM microcapsules.

lime-based mortars presented the higher water absorption values. On the other hand, the cement-based mortars showed lower water absorption.

This information was related with the flexural and compressive behaviour, because the increase in the porosity led to a decrease in the mechanical properties.

\subsection{Microstructure observations}

Tests using the electron microscope were performed in order to evaluate the existence of possible incompatibilities between the different materials present in the mortars.

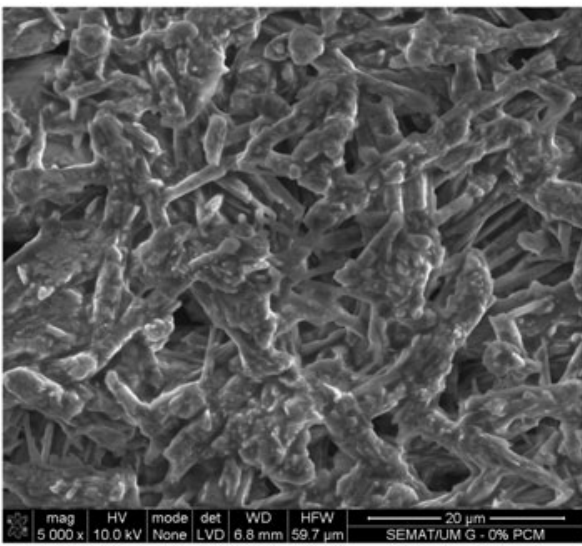

(a)

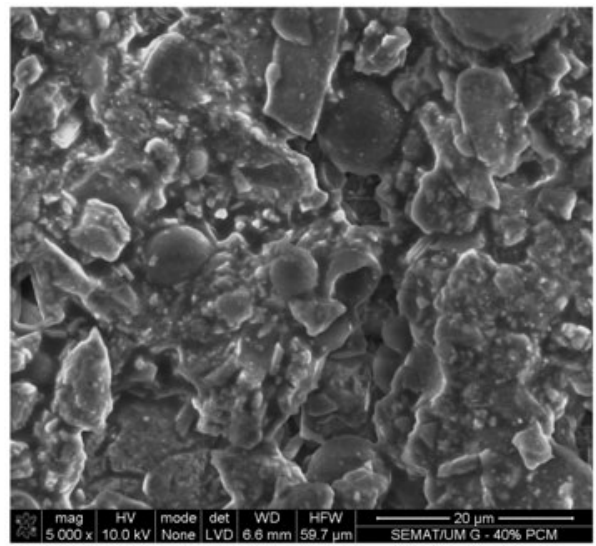

(b)

Figure 14. Microstructure of gypsum-based mortars: (a) Mortar without incorporation of PCM microcapsules (b) Mortar with incorporation of $40 \%$ of PCM microcapsules. 


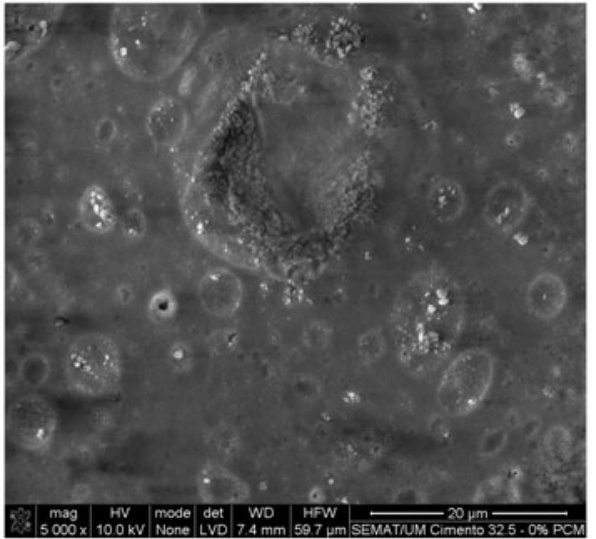

(a)

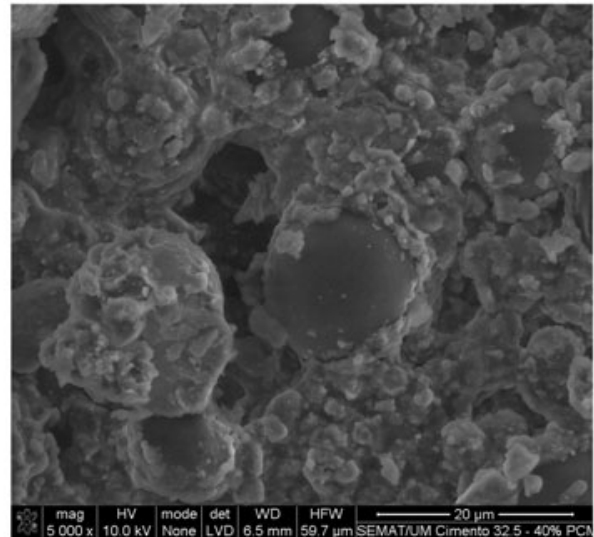

(b)

Figure 15. Microstructure of cement CEM II B-L $32.5 \mathrm{~N}$-based mortars: (a) Mortar without incorporation of PCM microcapsules (b) Mortar with incorporation of $40 \%$ of PCM microcapsules.

For these observations, it was possible to observe a good connection between the different materials evidenced by the absence of cracks in the microstructure of the developed mortars.

Figure 11 shows the microstructure of aerial lime-based mortars without PCM and with incorporation of $40 \%$ of PCM. However, these mortars exhibit some cracks caused by high shrinkage (Figure 12), which can justify the low mechanical strength observed in this type of mortars.

According to Figure 13, it was possible to verify a good interaction between different materials present in the hydraulic lime-based mortars, evidenced by the absence of cracks between the paste composed by the binder and aggregate, and with the PCM.

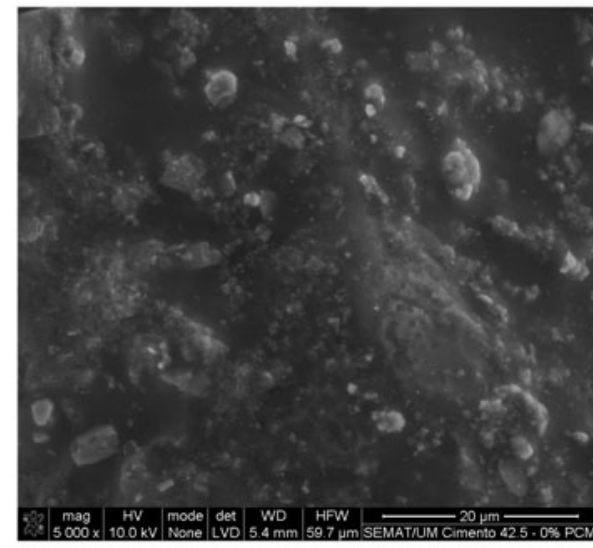

(a)

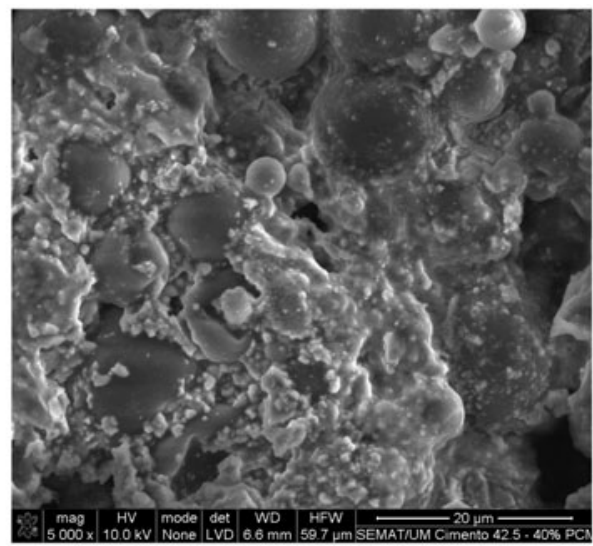

(b)

Figure 16. Microstructure of cement CEM I 42.5R-based mortars: (a) Mortar without incorporation of PCM microcapsules (b) Mortar with incorporation of 40\% of PCM microcapsules. 
Figure 14 shows the microstructure of gypsum-based mortars. It was possible to verify a change in the microstructure. However, it was possible to observe a good interaction between different materials.

Figures 15 and 16 show the microstructure of cement CEM II B-L 32.5N-based mortars and cement CEM I 42.5R-based mortars, evidencing again a good interaction between the various constituents of the mortar.

\section{Conclusion}

Based on the obtained results, it can be concluded that the incorporation of PCM in mortars for coating building interiors causes significant changes in their properties in fresh and hardened state. Regarding workability, it was verified that the incorporation of PCM caused an increase in the amount of water added to the mortar in order to give a suitable workability. This increase in the water/binder ratio is related to the fineness characteristics of PCM, requiring more water to obtain a homogeneous mortar. On the other hand, the study of mechanical strength (flexural strength, compressive strength and adhesion) showed a decrease with the incorporation of PCM. This phenomenon is a consequence of the presence of a larger amount of water, which leads to a higher porosity in mortars leading to decrease in the mechanical strengths. However, it was possible to obtain mortars classified at least as CSII for all the binders.

Based on this experimental work, it was possible to observe that the incorporation of PCM microcapsules in mortars can be seen as a viable solution for applications in the construction industry. Thus, it is possible to conclude that incorporating the PCM mortar can be performed successfully. Mortars with higher performance can be obtained and a higher content of binder is used, superplasticiser, while the inclusion of fibres can solve problems related to high shrinkage. All these procedures can be performed so as to provide an adequate workability to mortars and a similar aspect to the traditional mortars used in the construction industry.

\section{Acknowledgement}

This work was supported by Foundation for Science and Technology (FCT), followed by the grant number [SFRH/BD/95611/2013].

\section{References}

Ahmad, M., Bontemps, A., Sallée, H., \& Quenard, D. (2006). Thermal testing and numerical simulation of a prototype cell using light wallboards coupling vacuum isolation panels and phase change material. Energy and Buildings, 38, 673-681.

Athienitis, A., Liu, C., Hawes, D., Banu, D., \& Feldman, D. (1997). Investigation of the thermal performance of a passive solar test-room with wall latent heat storage. Building and Environment, 32, 405-410.

Bentz, D., \& Turpin, R. (2007). Potential applications of phase change materials in concrete technology. Cement \& Concrete Composites, 29, 527-532.

Cabeza, L., Castell, A., Barreneche, C., Gracia, A., \& Fernández, A. (2011). Materials used as PCM in thermal energy storage in buildings: A review. Renewable and Sustainable Energy Reviews, 15, 1675-1695.

Cunha, S., Aguiar, J. B., Ferreira, V. M., \& Tadeu, A. (2013). Influence of adding encapsulated phase change materials in aerial lime based mortars. Advanced Materials Research, 687, 255-261. 
Cunha, S., Aguiar, J. B., Kheradmend, M., Bragança, L., \& Ferreira, V. M. (2013). Thermal mortars with incorporation of PCM microcapsules. Restoration of Buildings and Monuments, 19, 171-177.

Cunha, S., Alves, V., Aguiar, J. B., \& Ferreira, V. M. (2012). Use of phase change materials microcapsules in aerial lime and gypsum mortars. Cement Wapno Beton, (Special Issue), 17-21.

Darkwa, K., O'Callaghan, P., \& Tetlow, D. (2006). Phase-change drywalls in a passive-solar building. Applied Energy, 83, 425-435.

Entrop, A., Brouwers, H., \& Reinders, A. (2011). Experimental research on the use of micro-encapsulated phase change materials to store solar energy in concrete floors and to save energy in Dutch houses. Solar Energy, 85, 1007-1020.

European Committee for Standardization (CEN). (1999). EN 1015-11:1999. Methods of test for mortar for masonry - Part 11: Determination of flexural and compressive strength of hardened mortar. Brussels: European Committee for Standardization.

European Committee for Standardization (CEN). (2000). EN 1015-12:2000. Methods of test for mortar for masonry - Part 12: Determination of adhesive strength of hardened rendering and plastering mortars on substrates. Brussels: European Committee for Standardization.

European Committee for Standardization (CEN). (2002). EN 1015-18:2002. Methods of test for mortar for masonry - Part 18: Determination of water absorption coefficient due to capillary action of hardened mortar. Brussels: European Committee for Standardization.

European Committee for Standardization (CEN). (2004). EN 1015-3:2004. Methods of test for mortar for masonry - Part 3: Determination of consistence of fresh mortar (by flow table). Brussels: European Committee for Standardization.

Jin, X., \& Zhang, X. (2011). Thermal analysis of a double layer phase change material floor. Applied Thermal Engineering, 31, 1576-1581.

Lin, K., Zhang, Y., Xu, X., Di, H., Yang, R., \& Qin, P. (2005). Experimental study of under-floor electric heating system with shape-stabilized PCM plates. Energy and Buildings, 37, 215-220.

Lucas, S., Ferreira, V., \& Aguiar, J. (2013). Latent heat storage in PCM containing mortarsStudy of microstructural modifications. Energy and Buildings, 66, 724-731.

National Laboratory of Civil Engineering (LNEC). (1993). Specification E 394, Concrete-Determination of water absorption by immersion. Lisbon: Gráficas do CDIT-LNEC (in Portuguese).

Portuguese Institute for Quality (IPQ). NP EN 998-1:2013. (2013). Specification for masonry mortars - Part 1: Plastering mortars for interior and exterior. Lisbon: Portuguese Institute for Quality (in Portuguese).

Schossig, P., Henning, H., Gschwander, S., \& Haussmann, T. (2005). Micro-encapsulated phase change materials integrated in to construction materials. Solar Energy Materials \& Solar Cells, 89, 297-306.

Sharma, A., Tyagi, V., Chen, C., \& Buddhi, D. (2009). Review on thermal energy storage with phase change materials and applications. Renewable and Sustainable Energy Reviews, 13, 318-345.

Shilei, L., Neng, Z., \& Guohui, F. (2006). Impact of phase change wall room on indoor thermal environment in winter. Energy and Buildings, 38, 18-24.

Tyagi, V., Kaushik, S., Tyagi, S., \& Akiyama, T. (2011). Development of phase change materials based microencapsulated technology for buildings: A review. Renewable and Sustainable Energy Reviews, 15, 1373-1391.

Zalba, B., Marín, J., Cabeza, L., \& Mehling, H. (2003). Review on thermal energy storage with phase change: Materials, heat transfer analysis and applications. Applied Thermal Engineering, 23, 251-283.

Zhang, Y., Zhou, G., Lin, K., Zhang, K., \& Di, H. (2007). Application of latent heat thermal energy storage in buildings: State-of-the-art and outlook. Building and Environment, 42, $2197-2209$. 